\title{
The potential legacy of cancer nanotechnology: celluar selection
}

\author{
Hirak K. Patra and Anthony Turner
}

\section{Linköping University Post Print}

\section{Tweet}

N.B.: When citing this work, cite the original article.

Original Publication:

Hirak K. Patra and Anthony Turner, The potential legacy of cancer nanotechnology: celluar selection, 2014, Trends in Biotechnology, (32), 1, 21-31.

http://dx.doi.org/10.1016/j.tibtech.2013.10.004

Copyright: Elsevier

http://www.cell.com/cellpress

Postprint available at: Linköping University Electronic Press

http://urn.kb.se/resolve?urn=urn:nbn:se:liu:diva-104126 
The Potential Legacy of Cancer Nanotechnology: Cellular Selection

Hirak K Patra ${ }^{1,2}$ and Anthony PF Turner ${ }^{l}$

${ }^{l}$ Biosensors and Bioelectronics Centre, IFM, Linkoping University, Linköping, 581 83, Sweden

${ }^{2}$ Integrative Regenerative Medicine Centre, IKE, Linkoping University, Linköping, 581 83, Sweden

Corresponding author: Turner, A.P.F. (anthony.turner@liu.se) 


\begin{abstract}
Overexpression of oncogenes or loss of tumour suppressors can transform a normal cell to a cancerous one, resulting in uncontrolled regulation of intracellular signaling pathways and immunity to stresses, which both pose therapeutic challenges. Conventional approaches to cancer therapy, although they are effective at killing cancer cells, may still fail due to inadequate biodistribution and unwanted side effects. Nanotechnology-based approaches provide a promising alternative, with the possibility of targeting cells at an early stage, during their transformation into cancer cells. This review considers techniques that specifically target those molecular changes, which begin in only a very small percentage of normal cells as they undergo transformation. These techniques are crucial for 'early-stage' diagnosis and therapy.
\end{abstract}




\section{Introduction}

The efficiency of chemotherapeutic protocols depends on the extent to which the drug can abate and eradicate cancerous cells without destroying normal healthy cells. Successful chemotherapy thus depends on the selective targeting of tumour cells [1, 2]. Indeed, a paradigm shift in chemotherapeutic research has occurred over the past decade, with the focus moving from the discovery of new cytotoxic drugs to the development of target-specific protocols, aided by nanotechnology, for the selective treatment of cancer [3]. Such specific targeting of cancer cells and the subsequent administration of a drug to a selected site can potentially enhance the chemotherapeutic prognosis and reduce unwanted side effects, as illustrated in the cartoon in Figure 1 (see http://www.cancer.gov/ for a detailed description of chemotherapy side-effects). In turn, the extent of selectivity of a chemotherapeutic drug towards the diseased cell is directly correlated with improved quality of life and survival rate of patients.

In 1906, Paul Ehrlich coined the term "magic bullet" to describe the ideal therapeutic reagent, possessing excellent targeting ability with super specificity [4]. Despite the many thousands of research articles that have since been published on drug targeting, this vision has remained an elusive goal in clinical practice. Although the available chemotherapeutic library has achieved moderate size and includes drugs that can target the intra-cellular signalling process, the cytoskeleton, DNA, the cell cycle and more, most drugs cannot differentiate between normal and cancer cells and, as a result, millions of patients are dying even after medication [5]. Moreover, during chemotherapy, patients often suffer from an increasing range of side effects ranging from infertility and memory loss to heart attack [6].

Nanoscale research has taken up this challenge. By improving site specificity, 
nanoscale technology offers the possibility of exceptional improvements in earlystage diagnosis and therapeutics, and also the potential for circumventing multi-drug resistance (MDR) [7,8].

Nanoscale materials are currently being investigated to improve their specificity towards cancer cells and towards sub-cellular compartments in order to reduce systemic toxicity. A substantial number of such materials have received clinical approval for reduction of drug toxicity, but have yet to be translated into therapies, due to concern about their eventual fate. Current efforts are therefore aimed at integrating specific targeting, real-time monitoring, biocompatibility, and excellent pharmacokinetic profiles $[9,10]$. The short- and long-term effects of such nanoscale materials are still unknown, but nanoscale research is presenting some tantalising questions. Might it be possible in the future for the pathologist to trace and diagnose the very first transformed cell that might lead to cancer? Could a doctor track down individual cancer cells and remove them from the circulation? Would it be possible to specifically instruct a cancer cell to self-destruct? Can a nanoscale material be designed to sense when, where and to what extent a drug should be released to avoid side effects and MDR?

Each of these functionalities could bring further complexity to the design [11]. Here, we focus on the trade-off between achieving such multifunctional "magic bullets" and specificity at the nanoscale in the effort to improve early stage detection and reduce collateral damage as side effects, central issues in the field of nanotechnology in cancer treatment.

\section{Nanoscale diagnosis: molecular and cellular selection}

Cancer is a heterogeneous disease that rapidly progresses to an uncontrollable stage after onset $[12,13]$. Thus, the survival and quality of life of patients depend 
directly on the stage at which the cancer has been detected; the most important factor in cancer management therefore is the detection of cancer cells at an early stage. Conventional detection systems that are regularly used by pathologists include the vacuum-assisted Mammotome ${ }^{\circledR}$ Breast Biopsy System for breast cancer, Papanicolau test to detect potentially pre-cancerous and cancerous processes for cervical cancer, Hemoccult Test for colorectal cancer, sputum cytology for lung cancer, digital rectal examination and prostate-specific antigen (PSA) level for prostate cancer, combined with imaging (endoscopy, X-ray, CT, MRI and ultrasound). However, none of these are very sensitive for an earlystage detection $[12,14]$. Nanotechnology-based approaches offer the possibility of reliably detecting and amplifying weak signals arising from a very early-stage transforming cell.

The detection of molecular biomarkers expressed during cancer onset is now an intensely researched area of nanotechnology and Tables 1 and 2 illustrate some recent developments. One such advanced example are 'Nanobiochips' that have been developed as integrated biosensors using quantum dots (QDs) that can potentially be used as multiplexed tools for quantitation of cancer markers such as carcinoembryonic antigen (CEA), cancer antigen (CA) 125, and Her-2/Neu (C-erbB2). They offer very high specificity in serum and saliva and may also be integrated with nanofluidic arrays to facilitate detection of sub cellular constituents $[15,16]$

\section{Early stage in vivo selection}

In vivo selection: In the ideal case, the transforming event would be probed by non-invasive means for the early-stage detection of cancer onset. An example of this type of approach was reported by Harisinghani et al. [17]. The authors used Ferumoxtran-10 (Combidex; Advanced Magnetics Inc, Cambridge, MA, USA), an 
ultrasmall, superparamagnetic, biodegradable iron oxide particle that is covered with a low-molecular-weight dextran as lymphotropic paramagnetic nanoparticles that facilitate detection of clinically occult lymph-node metastases by enhancing MRI contrast in patients with prostate cancer. Such metastases are undetectable by any other non-invasive approach. Probing the surrounding microenvironment by nanotechnology can provide further information on the onset and status of the early-stage disease [18]. Sustained angiogenesis is one of the important signatures of disease onset. The imaging of such events with very low amounts of epitope targeted by nanoparticles could be an important step for early-stage detection of cancer [19].

\section{Platform selection:}

Currently, there is no suitable platform to detect the presence of cancer biomarkers at ultralow concentrations, but promising results are emerging from nanotechnology-based approaches for the amplification and detection of such ultra-low signatures. Nanoscale surface patterning is one such example, where carbon nanotube patterning has been used for the detection of carcinoembryonic antigen (CEA), a glycosyl phosphatidyl inositol (GPI) cell surface-anchored glycoprotein involved during foetal development. The production of CEA stops before birth and its reappearance serves as an important cancer biomarker [20]. Surface-Enhanced Laser Desorption / Ionisation Time-of- Flight Mass Spectrometry (SELDI-TOF-MS), is a promising MS platform for the detection of trace amounts of peptides and small molecules at the specific tumour microenvironment, which is now under investigation in combination with nanomaterials for early-stage detection of cancer [21,22]. 
Nanotechnology-based multiplex platforms are also emerging as future diagnostic approaches for sensitive and reliable detection. One of the best examples is the 'bio-barcode' developed by Mirkin, which consists of twocomponent oligonucleotide-modified nanoparticle probes [23], which can detect zeptomolar concentrations. Such nanotechnology-based platforms thus show considerable promise for probing early cell transformations by both in vivo and ex vivo measurement [24].

\section{Nanocarriers in cancer cell selection}

Nanocarriers also offer a new mode of chemotherapeutic drug delivery. The unique physicochemical properties of nanomaterials can be exploited for developing such systems. Examples include: (i) tunable surface charge $(+v e)$ to promote electrostatic interaction with the comparatively negatively charged cancer cell surface (compared to normal cells) in order to stimulate endocytosis; (ii) tunable hydrophilic surfaces with stealth properties to prevent clearance by the reticulo-endothelial systems (RES) to prolong circulation times, thus avoiding opsonisation, the process by which foreign particles are altered by opsonins so as to become more readily and efficiently engulfed by phagocytes; and (iii) modification on the surface of nanoparticles to target specifically cancer cell membranes, the tumour microenvironment, or the sub cellular compartment. As a result of these approaches, nanocarriers can deliver high concentrations of drug to a selected site with reduced systemic cytotoxicity. One such example is described by Han et al., where they demonstrate that the antitumuor efficacy of nanoparticles carrying the anticancer drug camptothecin, can be enhanced by incorporating on average a single antibody Herceptin [25]. Table 3 summarises some nanotechnology-based drug delivery 
systems approved by the US FDA and European Medicines Agency (EMA) for clinical use (see http://www.accessdata.fda.gov/scripts/cder/drugsatfda/):

\section{Nanoscale cell selection}

\section{Passive selection:}

The biology of tumour growth and progression is exploited for passive selection by nanoparticle systems. Cancer cells have a faster proliferation rate than the surrounding normal cells and thus monopolise nutrients while generating more waste products, hence exerting stress on healthy cells. Gradually, cancer cells replace healthy cells and form a small cluster of rapidly proliferating cells, until the tumour reaches the diffusion limit size of around $2 \mathrm{~mm}^{3}$ [26]. At this point the normal cells cannot compete for an adequate supply of amino acids, nutrients, oxygen, and glucose, and are unable to manage the excreted waste. However, cancer cells survive in this limiting environment by inducing angiogenesis, overcoming the stress by increasing the surrounding vasculature. In such cases, there are always abnormalities in the basement membrane of the vessels due to defective angiogenesis, resulting in leaky vessels (gap size ranges from the nanometre to micrometer scale). Also, the lymphatic drainage network is abnormal and the asymmetric interstitial pressure (interstitium is the collagen-rich matrix that surrounds cancer cells and separates them from the vasculature) in the tumour inner core prevents normal diffusion of molecules [27].

Nanotechnology-based approaches exploit these opportunities to target tumour cells. Nanomaterials can escape through the leaky vasculature and can become trapped within the tumour due to the dysfunctional lymphatic drainage system. This phenomenon in fact generates an enhanced permeation and retention (EPR) effect for the nanomaterials in the tumor compared to conventional drug molecules, while 
avoiding normal healthy tissue, which has non-leaky vessels and a proper lymphatic drainage system [18]. Another mode of passive selection depends on the tunable surface charge of nanoparticles. The surface of tumour endothelial cells contains more negative charges due to the presence of sialic acids and overexpressed phospholipids, and these can be selected by positively charged nanoparticles due to electrostatic interactions [28].

\section{Active selection:}

Active selection of cancer cells is based on conjugation of biomolecules ("active biomolecules") to the surface of the nanomaterial system. In an ideal case, the targets are specific cancer surface molecules that are not expressed in other cell types and that bind to the active biomolecules. The primary objectives in such cases include: (i) specific recognition of cells via interaction of active biomolecules with respective ligands on the cell surface; (ii) avoidance of non-specific deposition of active biomolecules conjugated nanoparticles on the surface of non-target cells; (iii) increase in the local concentration of nanoparticles on target cells, to achieve the functional dose, before the drug becomes diluted through normal circulation and renal clearance; (iv) increase of cellular uptake of the drug in cancer cells through cell signalling and endocytosis; and (v) trafficking of nanomaterials to the target site through EPR. Surface-active biomolecules can bind either non-internalising target molecules or endocytosis-active molecules. In the former case, the nanoparticle is not engulfed, but resides on the surface of vascular endothelial cells; the drug-loaded nanoparticles can then release the drug with higher local concentration near the target site. In the latter case, a broad range of chemotherapeutic agents can be delivered including siRNAs and DNA binding drugs etc. Table 4 lists some nanoparticle systems under trial for active and passive selection of different cancer types. One such example is EndoTAG, 
formulated with neutral and positive lipids, and paclitaxel as cytostatic drug. The idea is to target passively target newly developing, negatively charged endothelial cells, which are especially needed for the growth of tumour blood vessels by the EndoTAG with positively charged lipids on the surface. The EndoTAG loaded with paclitaxel works on the activated dividing endothelial cells. As a result, EndoTAG is targeting the blood supply system to tumours without affecting the supply to non-activated endothelial cells of the surrounding healthy tissue. EndoTAG is thus expected to prevent new blood vessel formation to inhibit tumour growth. Figure 2 illustrates active versus passive modes of selection by nanomaterials.

In summary, the passive selection of cancer cells is guided by the enhanced permeability and retention effect, electrostatic interactions (in case of positively charged nanomaterial systems) and the high metabolic rate of the cancer cells that indirectly leads to engulfment of nanomaterials - already present in the vicinity of cancer cells - due to EPR and phagocytosis-like activities. In active selection the nanoparticles are attached to either an antibody, or carrier protein or a ligand, which will allow it to selectively find and dock on the target cell having the receptor for the attachment.

\section{Systemic selection}

Systemic selection targets uncontrolled replication of cancer cells, angiogenesis during tumour growth, and metastasis. These events are not independent and may occur simultaneously, depending on the stage of the cancer. This heterogeneity of cancer is also being tackled by the design of multifunctional nanoscale systems for anticancer therapy.

Selection through uncontrolled proliferation 
Cell cycle regulation is highly conserved to ensure normal growth and the proper architecture of tissues and organs. Damage to this regulation can induce an uncontrolled cell growth [29], which leads to the emergence of a more efficient proliferating machinery that replicates the cell without control. Such cells over express altered surface molecules, which can become targets for nanoparticle-based systems equipped with antibodies (against surface peptides or glycoproteins), aptamers (against surface antigens), or specific ligands (for receptors) [30]. Cancer cell surface host molecules that are regularly selected for study are: (i) folate receptor; (ii) transferrin receptors; and (iii) endothelial receptors.

Folic acid: Most cancer cell surfaces (e.g., breast, ovarian, prostate, lung, liver, head and neck, and brain cancer) express elevated levels of folate receptors compared to normal cells. Differences in folic acid transport between cancer and normal cells make the folate receptor an appropriate target. Although normal cells allow only transport the unconjugated reduced form of folic acid across their membrane, cancer cells bind the nanoconjugated form of folic acid with high affinity. In addition, folate receptors are expressed asymmetrically on the luminal surface of epithelia and are thus inaccessible to the circulation. However, the precise expression pattern of folate receptors is lost in cancer cells and the polarised distribution of folate receptors due to overexpression helps selection by folic-acid-conjugated nanomaterials, because it no longer is hidden from circulation [31].

Transferrin: The uncontrolled rapid proliferation rate of cancer cells compared to normal cells requires a large amount of iron for cell division. For this reason, cancer cells express extremely high levels of transferrin; a membrane receptor that binds and transports iron into cells via endocytosis. Transferrin is thus another potential target molecule for nanoconjugated systems for the selection of cancer cells 
[26]. In addition, during metastasis and drug resistance (the two most difficult situations in cancer management), the expression of transferrin receptors is upregulated compared to normal healthy cells. Clinical trials are ongoing to validate transferrin targeting for cancer cell selection [32].

Epidermal growth factor receptors (EGFRs): Intracellular growth signalling is essential for the rapid growth and proliferation of cancer cells, leading to upregulation of growth factor receptor (EGFR) and human epidermal receptor (HER) on the cancer cell surface. These receptors transduce intracellular proliferation signals upon binding growth factor ligands. These receptors are favoured targets for cancer cell selection [33]. Herceptin, comprising a monoclonal antibody that targets HER, provides one example. It has been used in nanoconjugated systems for the selection of cancer cells expressing HER [34].

\section{Nanomaterials: intrinsic cell selection}

Recent reports describe nanomaterials without any targeting molecules on the surface, which can nevertheless be selectively taken up and produce a cell-specific response. The first report in this direction was from Patra et al., who showed that citrate-capped gold nanoparticles can selectively target human lung epithelial cells (A549), without interacting with BHK21 kidney cells and HepG2 liver cells, as illustrated in Figure 3A [35]. This report first coined the term 'cell selective' nanoparticles and is now supported by a large number of new reports along the same lines [36], although the exact molecular mechanism is still unknown. The asymmetric distribution of the nanoparticles just outside the nucleus suggests the possibility of sub-cellular selection, as illustrated in Figure 3B and C. Later, Fraga et al. extensively investigated HepG2 cells [37] and also found that citrate and 1-mercaptoundecanoic acid (11-MUA) 
coated gold nanoparticles are taken up by the human liver cancer cells with indicative DNA damage.

The intrinsic selection by nanoparticles is likely dependent not only on the composition of the material itself, but also its size, shape, charge and surface conjugations. Thus, different cell types may react to different aspects of the particle. For example, Sohaebuddin et al., using a set of multi-wall carbon nanotubes, silicon oxide and titanium oxide nanoparticles, showed that the mechanism of response to the particles, even using the same nanomaterial, varied from one cell type to the next [38]. In addition, they have found that the response is variable between cell types and they explained such selection due to the physiological function of the cell types. Patra et al. undertook extensive investigations to find the optimum hydrodynamic parameters of the nanoparticles for such selections and found neither size nor surface zeta potential (the indirect measurement of the surface charge of the particles in colloidal system) alone determined the cellular interactions of gold nanoparticles. A complex interplay among hydrodynamic diameter, surface charge, surface functionalisation, and cell cycle stage determined the outcome [28, 39-41].

The geometry of a nanoparticle may also play a role. Jin et al. proposed a quantitative model for endocytosis rate based on nanoparticle geometry. They have shown sizeand geometry-dependent cellular uptake and expulsion of single-walled carbon nanotubes and gold nanoparticles by single particle tracking [42]. Several investigations are ongoing to correlate the intrinsic effect of such nanomaterial properties with cellular function, uptake, transportation and toxicity in vitro and in vivo [43, 44]. Below, we highlight the rationale for these studies and review the unusual interactions of nanomaterials with tissue types to provide a perspective on the long-term implications of these findings. 


\section{Tissue specific cell selection}

Recent statistics show that one in four deaths are due to cancer. In males, estimated new cases in 2013 for prostate cancer are estimated at $28 \%$ and at $14 \%$ for lung cancer. Similarly, in females, new cases are estimated at $29 \%$ for breast cancer and $14 \%$ for lung cancer [5]. Thus, it is reasonable to focus on these cancer types in the search for cellular target selection by nanomaterial systems.

Prostate cancer selection: The prostate cancer cell surface contains prostate specific membrane antigen (PSMA). This antigen (a trans-membrane glutamate carboxypeptidase II glycoprotein) is widely used for selecting prostate cancer cells [45]. Antibodies and aptamers specific for PSMA are used for diagnostic and therapeutic purposes [46]. In vivo studies show that targeted nanoparticle systems can effectively select prostate cancer cells (LNCaP prostate cancer cells) and inhibit tumour growth compared to non-targeted and bare drug [47]. An alternative involves folate, as discussed in the section above. Similarly, $\sigma$ factors expressed by the prostate cancer cell surface can be used for selection, but this is not restricted to prostate cancer only [48].

Breast cancer selection: As discussed previously, one of the most important surface markers overexpressed in breast cancer is HER-2, and Herceptin is commercially used for the successful treatment of metastatic breast cancer [49]. Nanoparticle systems conjugated with HER-2 antibody fragment are being investigated for selective imaging, drug delivery and gene silencing through siRNA [50, 51]. As in the case of prostate cancer, folate-receptor-mediated nanoparticle systems are also being developed. For localised breast cancer selection, another important molecular marker is luteinising hormone-releasing hormone (LHRH) receptor on breast cancer cells. A superparamagnetic iron oxide nanoparticle (SPIONs) based system has been 
developed for detection of breast cancer metastasis (LHRH-conjugated magnetic iron oxide nanoparticles) [52]. Importantly, the in vivo study showed that the LHRHSPIONs nanoparticle system did not accumulate in the livers of normal mice, suggesting that off-target effects were limited. By contrast, the non-targeted controls accumulated in the liver, making this study one of the best examples of successful selection of specific cancer cells by nanoparticles [52].

Lung cancer selection: Although lung cancer is one of the leading causes of death worldwide, there is no established specific selection system developed for its diagnosis and therapy [5]. As a result, conventional chemotherapy and radiation protocols used along with surgical procedures, resulting in extensive side effects and quality poor life [53]. Thus there is a great need to design better therapies. The landmark work of Chen et al. [54] resulted in an aptamer that can specifically select small-cell lung cancer. The in vitro study showed specific cellular selection over different kinds of cancer cells including leukaemia, and liver and even lung adenocarcinoma. The aptamer was conjugated with magnetic nanoparticles for the selective targeting and isolation of small-cell lung cancer cells and later on, detection through fluorescent nanoparticles. This is the first successful example of small-cell lung cancer cell selection, isolation and detection by a nanoparticle system $[26,54]$.

\section{Specific selection using nanomaterials}

Species-specific selection: The first reported species specificity showed that gold nanoparticles can interact with the human lung epithelial cancer cell line (A549), but not with baby hamster kidney cell line (BHK21) [35]. Such evidence of selectivity was again reported recently using different sizes of copper nanoparticles. The differential behaviour has been observed for mammalian (H4IIE and HepG2) and piscine cell lines (PLHC-1 and RTH-149) [55]. These results may aid in the design of 
therapies against cancers induced by other species such as oncoviruses. In such cases the nano-aided system might be helpful in differentiating the transformed cells from the host.

Sex-specific selection: Recent in vivo reports show gold nanoparticles can induce different interactions in males and females and indicate a sex bias in nanoparticle activity. One study showed that gold nanoparticles can induce significant kidney damages in female mice, while inducing liver damage in males [56]. The mechanism is yet to be established, but this effect should be considered when metallic nanoparticles are applied for chemotherapeutic purposes.

\section{Multidrug resistance: cell selection}

Development of tumour drug resistance is now considered a major hurdle restricting chemotherapeutic success. In multidrug resistance (MDR), a cancer cell can escape the effects of a wide range of chemotherapeutic drugs. In such cases, exposure of a cancer cell to a single drug gradually stimulates the cell to develop direct resistance to that group of drugs (structurally similar) or even cross-resistance with other structurally non-similar drugs. The molecular basis of this effect is the presence of ATP-binding cassette $(\mathrm{ABC})$ transporters that pump out the chemotherapeutic toxic drugs from cancer cells. P-glycoprotein (P-gp) is one of the well-established ABC transporters present on the cell surface of multidrug resistant tumour cells. For a summary of the current status and the strategies to overcome MDR, see Saraswathy et al. [57]. MDR and possibilities for nano-based approaches to conquer MDR, are illustrated in Figure 4 and discussed below. Table 5 lists nanotechnology-based approaches for overcoming MDR that are currently undergoing clinical trials.

\section{Redressing chemotherapy regimens}


Nanotechnology enables the simultaneous presentation of multiple drugs around a central nanoparticle scaffold [58], allowing clinicians to administer the maximum number of chemotherapeutic drugs at the highest possible dose in the hope that the cancer cell will not be resistant to all the drugs. It is expected that threshold drug concentrations can be reached for effective chemotherapy even after the drug has been pumped out by the multidrug-resistant cancer cell.

Targeting MDR key player P-gp

P-gp is one of the key players in MDR. Direct targeting of P-gp and its depletion using nano-conjugated antibody may improve chemotherapy protocols in two ways. Firstly, P-gp proteins are only overexpressed on multidrug-resistant cell surfaces, and thus conjugating nanoparticles with P-gp antibodies endows selectivity for multidrugresistant cells. Secondly, by inhibiting the activity of the P-gp, the drugs allow conventional chemotherapeutic agents to exert their normal effects. Another option is use of an anti-sense RNA for knocking out the expression of P-gp at the translational level. Patil et al. reported one such example in vitro and in vivo, where coencapsulation of paclitaxel (a chemotherapeutic agent) and siRNA for P-gp in a single poly(D,L-lactide-co-glycolide) nanoparticle overcame tumour drug resistance [59].

\section{Nanoscale cocktail}

A combination of different modules in a single nanoparticle system to bypass tumor drug resistance is in a clinical trial. In this example, TOCOSOL, a paclitaxel and vitamin E nanoscale emulsion, is equipped with a P-gp inhibitor TGPS [60].

\section{Next-generation nanodrugs: cell selection}


Design of the first generation of nanodrugs sought mainly to increase the bioavailability of drugs at the tumour site and, to some extent, to reduce their side effects. The first nanodrug approved by the FDA was the paclitaxel protein-bound particle Abraxane that was indicated for the first-line treatment of patients with metastatic adenocarcinoma in 2005, and since then the list has expanded as shown in Table 3. In 2012 Abraxane was approved for injectable suspension in non-small cell lung cancer (NSCLC). The degrees of freedom allowed for next-generation nanodrugs is likely to expand compared to earlier liposome systems with nextgeneration nanotherapeutics for cancer management being designed for target selection along with increased efficiency, as illustrated in Figure 5. One such example is BIND-014 that targets the prostate-specific membrane antigen (PSMA). This compound has already completed a phase 1 clinical trial, which resulted in promising for anti-tumour activity in patients with advanced and metastatic solid-tumour cancers.

The next generation chemotherapy is expected to be based on nanotheranostics, the combination of both diagnostic and therapeutic elements at the nanoscale. Such systems, comprising drug and molecular targeting agents, deliver diagnostic capabilities along with therapy, and are emerging as the next generation of multifunctional remedies. Targeted delivery systems with nanoscale dimensions, such as liposomes, micelles, dendrimers, and different nanostructures have already been reported. However, real time tracking of the above-mentioned systems is still under investigation. Future delivery systems should release the drug from the carrier to its target in a well-controlled manner through site-specific stimuli such as inflammation, $\mathrm{pH}$, and ionic strength. Again, the heterogeneity and super adaptive nature of cancer require novel therapeutic protocols that must be smart and custom-fitted to the cancer 
type and individual patient. One such prototype system has been developed by Patra et al recently [61], where they have synthesised core-shell nanocomposite micelles using polystyrene block poly acrylic acid (PS- $b$-PAA) and SPIONs as a stimulus responsive targeted (by folic acid) nanotheranostic module for the controlled release of drug into a tumour site with real-time monitoring possibilities through MRI. The findings suggest the possibility of next-generation smart theranostic micellar nanostructures as biocompatible, cancer cell target specific, tumourmicroenvironment sensitive, $\mathrm{pH}$-responsive systems with future provision for earlystage tumour sensing, tracking, and therapy, which is selective for cancer cells.

\section{Concluding remarks and future prospective}

Lack of selectivity is still the major challenge in cancer management in terms of both diagnosis and therapy. Most current methods for cancer detection still lack sensitivity and have relatively high detection limits and are thus unable to track cancer at an early stage. Nanoparticle systems provide a new method for recognition, delivery and extension of effective drug lifetimes. Although still in its infancy, research on nanoparticles has resulted in systems that are able to target specifically cells, subcellular components, and the key molecules involved in tumour growth and metastasis. Recent reports include metallic, inorganic, and polymeric nanomaterials capable of changing the biodistribution of drug molecules at the cellular and subcellular level, but challenges still remain in terms of selectivity. In addition to improving this parameter, future work will seek to control when and how a drug is released at the target site to tackle the heterogeneity of cancer, where combinations of different drugs may need to be administered in different time frames. Nanoparticle systems offer the opportunity to integrate both the drug and the detection molecule to 
create a multifunctional platform that can simultaneously target the correct site, and allow monitoring and release of the drug, thus fulfilling a prime requirement for personalised medicine. Such a platform would have the potential to control remotely the drug release profile and hence could also mitigate problems associated with MDR. However, most nanomaterials have yet to reach clinical trials. More work is thus needed before we can resolve whether nanoparticles are indeed the long-anticipated "magic bullets" for treating cancer.

Acknowledgement The authors wish to acknowledge IGEN Center, Linkoping University, Sweden for providing the postdoctoral fellowship. The authors also thank Dr. Suryyani Deb for providing valuable technical suggestions during preparation of the manuscript. 


\section{Reference}

[1] Wu, J. et al (2012) Targeted therapy: its status and promise in selected solid tumors part I: areas of major impact. Oncology 26, 936-943.

[2] Joseph, S. O. et al (2012) Targeted therapy: its status and promise in selected solid tumors. Part II: Impact on selected tumor subsets, and areas of evolving integration. Oncology 26, 1021-1030.

[3] Peer, D. et al (2007) Nanocarriers as an emerging platform for cancer therapy. Nature nanotechnology 2, 751-760.

[4] Strebhardt, K. \& Ullrich, A. (2008) Paul Ehrlich's magic bullet concept: 100 years of progress. Nature Reviews Cancer 8, 473-480.

[5] Siegel, R. et al (2013) Cancer statistics, 2013. CA: a cancer journal for clinicians 63, 11-30.

[6] Bonita, R. \& Pradhan, R. (2013) Cardiovascular Toxicities of Cancer Chemotherapy. In Seminars in oncology 40, 156-167.

[7] Misra, R. et al (2010) Cancer nanotechnology: application of nanotechnology in cancer therapy. Drug Discovery Today 15, 842-850.

[8] Heath, J. R. \& Davis, M. E. (2008) Nanotechnology and cancer. Annu. Rev. Med. 59, 251-265.

[9] Kievit, F. M. \& Zhang, M. (2011) Cancer nanotheranostics: improving imaging and therapy by targeted delivery across biological barriers. Advanced Materials 23, 217-247.

[10] Cole, A. J. et al (2011) Cancer theranostics: the rise of targeted magnetic nanoparticles. Trends in biotechnology 29, 323-332.

[11] Cheng, Z. et al (2012). Multifunctional nanoparticles: cost versus benefit of adding targeting and imaging capabilities. Science 338, 903-910.

[12] Ferrari, M. (2005) Cancer nanotechnology: opportunities and challenges. Nature Reviews Cancer 5, 161-171.

[13] Choi, Y. E. (2010). Nanotechnology for early cancer detection. Sensors 10, 428-455.

[14] Tüdös, A. J. et al (2001) Trends in miniaturized total analysis systems for point-of-care testing in clinical chemistry. Lab on a Chip 1, 83-95.

[15] Jokerst, J. V. et al (2009) Nano-bio-chips for high performance multiplexed protein detection: determinations of cancer biomarkers in serum and saliva using quantum dot bioconjugate labels. Biosensors and Bioelectronics 24, 3622-3629

[16] Perfézou, M. et al (2012). Cancer detection using nanoparticle-based sensors. Chemical Society Reviews 41, 2606-2622.

[17] Harisinghani, M. G. (2003). Noninvasive detection of clinically occult lymph-node metastases in prostate cancer. New England Journal of Medicine 34, 2491-2499.

[18] Liu, J. (2010). Multiplexed detection and characterization of rare tumor cells in Hodgkin's lymphoma with multicolor quantum dots. Analytical chemistry 82, 6237-6243.

[19] Liu, P. (2013). Micro-CT Molecular Imaging of Tumor Angiogenesis Using a Magnetite Nano-Cluster Probe. Journal of Biomedical Nanotechnology 9, 1041-1049.

[20] Kwon, T. et al (2013). Carbon Nanotube-Patterned Surface-Based Recognition of Carcinoembryonic Antigens in Tumor Cells for Cancer Diagnosis. The Journal of Physical Chemistry Letters 4, 1126-1130.

[21] Wulfkuhle, J. D. et al (2003). Proteomic applications for the early detection of cancer. Nature reviews cancer 3, 267-275.

[22] Petricoin, E. F., \& Liotta, L. A. (2004). SELDI-TOF-based serum proteomic pattern diagnostics for early detection of cancer. Current Opinion in Biotechnology 15(1), 24-30.

[23] Stoeva, S. I. et al (2006). Multiplexed detection of protein cancer markers with biobarcoded nanoparticle probes. Journal of the American Chemical Society 128, 8378-8379.

[24] Turner, A.P.F. (2013) Biosensors: sense and sensibility. Chemical Society Reviews 42, 31843196

[25] Han, H., \& Davis, M. E. (2013). Single antibody, targeted nanoparticle delivery of camptothecin. Molecular pharmaceutics10, 2558-2567. 
[26] Brannon-Peppas, L.\& Blanchette, J. O. (2012) Nanoparticle and targeted systems for cancer therapy. Advanced drug delivery reviews 56, 1649-1659.

[27]Peer, D. (2007) Nanocarriers as an emerging platform for cancer therapy. Nature nanotechnology 2, 751-760.

[28] Patra, H. K. \& Dasgupta, A. K. (2012) Cancer cell response to nanoparticles: criticality and optimality. Nanomedicine: Nanotechnology, Biology and Medicine 8, 842-852.

[29] Baumann, K. (2013). Cell cycle: A checkpoint escape. Nature Reviews Molecular Cell Biology 14, 267-267.

[30] Byrne, J. D. et al (2008). Active targeting schemes for nanoparticle systems in cancer therapeutics. Advanced drug delivery reviews 60, 1615-1626.

[31] Talekar, M. et al (2011). Targeting of nanoparticles in cancer: drug delivery and diagnostics. Anti-Cancer Drugs 22, 949-962.

[32] Weaver, M. \& Laske, D. W. (2003) Transferrin receptor ligand-targeted toxin conjugate (TfCRM107) for therapy of malignant gliomas. Journal of neuro-oncology 65, 3-14.

[33] Laskin, J. J. \& Sandler, A. B. (2004) Epidermal growth factor receptor: a promising target in solid tumours. Cancer treatment reviews 30, 1-17.

[34] Izumi, Y. et al (2002) Tumour biology: herceptin acts as an anti-angiogenic cocktail. Nature 416, 279-280.

[35] Patra, H. K. et al (2007) Cell selective response to gold nanoparticles. Nanomedicine: Nanotechnology, Biology and Medicine 3, 111-119.

[36] Alkilany, A. M. \& Murphy, C. J. (2010) Toxicity and cellular uptake of gold nanoparticles: what we have learned so far?. Journal of Nanoparticle Research 12, 2313-2333.

[37] Fraga, S. et al (2013) Influence of the surface coating on the cytotoxicity, genotoxicity and uptake of gold nanoparticles in human HepG2 cells. Journal of Applied Toxicology (DOI: 10.1002/jat.2865)

[38] Sohaebuddin, S. K. et al (2010) Nanomaterial cytotoxicity is composition, size, and cell type dependent. Particle and fibre toxicology 7, 22-39

[39] Patra, H. K. et al (2011) Dual role of nanoparticles as drug carrier and drug. Cancer Nanotechnology 2, 37-47.

[40]Deb, S. et al (2011) Multistability in platelets and their response to gold nanoparticles. Nanomedicine: Nanotechnology, Biology and Medicine 7, 376-384.

[41] Patra, H. K. \& Dasgupta, A. K. (2011) Arginine an Enhancer of Gold Nanoparticle Induced Blocking of S-Phase Cell Cycle in HL60. Advanced Science Letters 4, 11-12.

[42] Jin, H. et al (2009) Size-dependent cellular uptake and expulsion of single-walled carbon nanotubes: single particle tracking and a generic uptake model for nanoparticles. ACS Nano 3, 149-158.

[43] Ferrari, M. (2009) Intravascular delivery of particulate systems: does geometry really matter?. Pharmaceutical research 26, 235-243.

[44] Malugin, A. \& Ghandehari, H. (2010) Cellular uptake and toxicity of gold nanoparticles in prostate cancer cells: a comparative study of rods and spheres. Journal of Applied Toxicology 30, 212-217.

[45] Wang, X. et al (2007) Targeted treatment of prostate cancer. Journal of cellular biochemistry 102, 571-579.

[46] Hrkach, J. et al (2012). Preclinical development and clinical translation of a PSMA-targeted docetaxel nanoparticle with a differentiated pharmacological profile. Science translational medicine 4, 128ra39-128ra39.

[47] Farokhzad, O. C. et al (2006). Targeted nanoparticle-aptamer bioconjugates for cancer chemotherapy in vivo. Proceedings of the National Academy of Sciences 103, 6315-6320.

[48] Banerjee, R. et al (2004) Anisamide-targeted stealth liposomes: A potent carrier for targeting doxorubicin to human prostate cancer cells. International journal of cancer 112, 693-700. 
[49] Baselga, J. et al (1998). Recombinant humanized anti-HER2 antibody (Herceptin ${ }^{\mathrm{TM}}$ ) enhances the antitumor activity of paclitaxel and doxorubicin against HER2/neu overexpressing human breast cancer xenografts. Cancer Research 58, 2825-2831.

[50] Steinhauser, I. et al (2006). Trastuzumab-modified nanoparticles: optimisation of preparation and uptake in cancer cells. Biomaterials 27, 4975-4983.

[51] Tan, W. B. et al (2007). Quantum-dot based nanoparticles for targeted silencing of HER2/neu gene via RNA interference. Biomaterials 28, 1565-1571.

[52] Leuschner, C. et al (2006). LHRH-conjugated magnetic iron oxide nanoparticles for detection of breast cancer metastases. Breast cancer research and treatment 99, 163-176.

[53] Chen, A. B. (2013) Palliative Radiation Therapy Practice in Patients With Metastatic NonSmall-Cell Lung Cancer: A Cancer Care Outcomes Research and Surveillance Consortium (CanCORS) Study. Journal of Clinical Oncology, 31, 558-564.

[54] Chen, H. W et al (2008). Molecular Recognition of Small-Cell Lung Cancer Cells Using Aptamers. ChemMedChem, 3, 991-1001.

[55] Song, L. et al (2013). Species-specific toxicity of copper nanoparticles among mammalian and piscine cell lines. Nanotoxicology, (DOI:10.3109/17435390.2013.790997), 1-11.

[56] Chen, J. et al (2013). Sex differences in the toxicity of polyethylene glycol-coated gold nanoparticles in mice. International journal of nanomedicine 8, 2409.

[57] Saraswathy, M. \& Gong, S. (2013). Different Strategies to Overcome Multidrug Resistance in Cancer. Biotechnology advances (DOI: 10.1016/j.biotechadv.2013.06.004)

[58] Hu, C. M. J (2010). Nanoparticle-assisted combination therapies for effective cancer treatment. Therapeutic Delivery 1, 323-334

[59] Patil, Y. B. (2010). The use of nanoparticle-mediated targeted gene silencing and drug delivery to overcome tumor drug resistance. Biomaterials 31, 358-365

[60] Lissianskaya, A. et al (2004). Paclitaxel injectable emulsion: Phase 2a study of weekly administration in patients with platinum-resistant ovarian cancer. In Proc Am Soc Clin Oncol 22,5047

[61] Patra, H. K. et al (2013), MRI-Visual Order-Disorder Micellar Nanostructures for Smart Cancer Theranostics. Advanced Healthcare Materials. doi: 10.1002/adhm.201300225

[62]Liu, D. et al (2013). Gold Nanoparticle-Based Activatable Probe for Sensing Ultra-Low Levels of Prostate Specific Antigen. ACS nano (DOI: 10.1021/nn401837q).

[63] Huang, Y. W. et al (2013) Real-Time and Label-Free Detection of the Prostate-Specific Antigen in Human Serum by a Novel Polycrystalline-Silicon Nanowire Field-Effect Transistor Biosensor. Analytical Chemistry (DOI: 10.1021/ac401610s).

[64]Laing, S. et al (2013). Immunoassay Arrays Fabricated by Dip-Pen Nanolithography with Resonance Raman Detection. Analytical chemistry (DOI: 10.1021/ac4009012).

[65] Schol, D. et al (2013). Anti-PSMA antibody-coupled gold nanorods detection by optical and electron microscopies. Micron (DOI: 10.1016/j.micron.2013.05.003).

[66] Mohan, K. (2013) Sub-nanomolar Detection of Prostate Specific Membrane Antigen in Synthetic Urine by Synergistic, Dual Ligand Phage. Journal of the American Chemical Society (DOI: 10.1021/ja4028082).

[67] Park, J. (2013) HER2-specific Aptide Conjugated Magneto-nanoclusters for Potential Breast Cancer Imaging and Therapy. J. Mater. Chem. B (DOI: 10.1039/C3TB20613K).

[68] Han, J. H. et al (2012). Ultrasensitive On-Chip Immunoassays with a Nanoparticle-Assembled Photonic Crystal. ACS nano 6, 8570-8582.

[69] Kierny, M. R. et al (2012). Detection of biomarkers using recombinant antibodies coupled to nanostructured platforms. Nano reviews 3, 17240.

[70] Valentini, P. et al (2013). Gold Nanoparticles-Based Colorimetric Discrimination of CancerRelated Point Mutations with Picomolar Sensitivity. ACS nano (DOI: 10.1021/nn401757w).

[71] Yang, J. et al (2012). Distinguishing breast cancer cells using surface-enhanced Raman scattering. Analytical and bioanalytical chemistry 402, 1093-1100. 
[72] Hua, X. et al (2013). Selective collection and detection of MCF-7 breast cancer cells using aptamer-functionalized magnetic beads and quantum dots based nano-bio-probes. Analytica Chimica Acta (DOI: 10.1016/j.aca.2013.06.001).

[73] Peterson, V. M. et al (2012). Orthogonal amplification of nanoparticles for improved diagnostic sensing. ACS nano 6, 3506-3513.

[74] Lu, W. et al (2010). Multifunctional oval-shaped gold-nanoparticle-based selective detection of breast cancer cells using simple colorimetric and highly sensitive two-photon scattering assay. ACS nano 4, 1739-1749.

[75] Li, T. et al (2010). Detection of breast cancer cells specially and accurately by an electrochemical method. Biosensors and Bioelectronics 25, 2686-2689.

[76] Nima, Z. A. et al (2013). Single-walled carbon nanotubes as specific targeting and Raman spectroscopic agents for detection and discrimination of single human breast cancer cells. Journal of biomedical optics 18, 055003-055003.

[77] Kim, S. et al (2013). Circulating Tumor Cell Microseparator Based on Lateral Magnetophoresis and Immunomagnetic Nanobeads. Analytical chemistry 85, 2779-2786.

[78] Yang, J. et al (2008). Fluorescent magnetic nanohybrids as multimodal imaging agents for human epithelial cancer detection. Biomaterials 29, 2548-2555.

[79] Ma, J. et al (2010). Synthesis of magnetic and fluorescent bifunctional nanocomposites and their applications in detection of lung cancer cells in humans. Talanta 81, 1162-1169.

[80] Jokerst, J. V. (2012). Gold Nanorods for Ovarian Cancer Detection with Photoacoustic Imaging and Resection Guidance via Raman Imaging in Living Mice. ACS nano 6, 1036610377.

[81] Kabanov, A.V. et al (2002) Pluronic block copolymers for overcoming drug resistance in cancer. Adv Drug Deliv Rev 54, 759-779.

[82] Alakhov, V.Y. et al. (1999) Block copolymer-based formulation of doxorubicin. From cell screen to clinical trials. Colloids Surf B: Biointerfaces 16, 113-134.

[83] Dong, X. et al (2009) Doxorubicin and paclitaxel-loaded lipid-based nanoparticles overcome multidrug resistance by inhibiting P-glycoprotein and depleting ATP. Cancer Res 69, 39183926.

[84] Koziara, J.M. et al. (2006) In vivo efficacy of novel paclitaxel nanoparticles in paclitaxelresistant human colorectal tumors. J Control Release 112, 312-319.

[85] Hornicek, F. J. (2013). Lipid-functionalized Dextran Nanosystems to Overcome Multidrug Resistance in Cancer: A Pilot Study. Clinical Orthopaedics and Related Research ${ }^{\circledR}$ 471, 915925.

[86] Miao, J. et al (2013). Drug resistance reversal activity of anticancer drug loaded solid lipid nanoparticles in multi-drug resistant cancer cells. Colloids and Surfaces B: Biointerfaces (DOI: 10.1016/j.colsurfb.2013.03.037).

[87] Wong, H.L. et al (2006). A new polymer-lipid hybrid nanoparticle system increases cytotoxicity of doxorubicin against multidrug-resistant human breast cancer cells. Pharm Res $23,1574-1585$.

[88]Zhang, X., Guo et al (2012). Dual-functional liposome for tumor targeting and overcoming multidrug resistance in hepatocellular carcinoma cells. Biomaterials 33, 7103-7114.

[89]Zhao, Y. Z. et al (2012). Epirubicin loaded with a novel propylene glycol liposome significantly overcomes multidrug resistance in breast cancer. Cancer letters 330, 74-83 
Figures

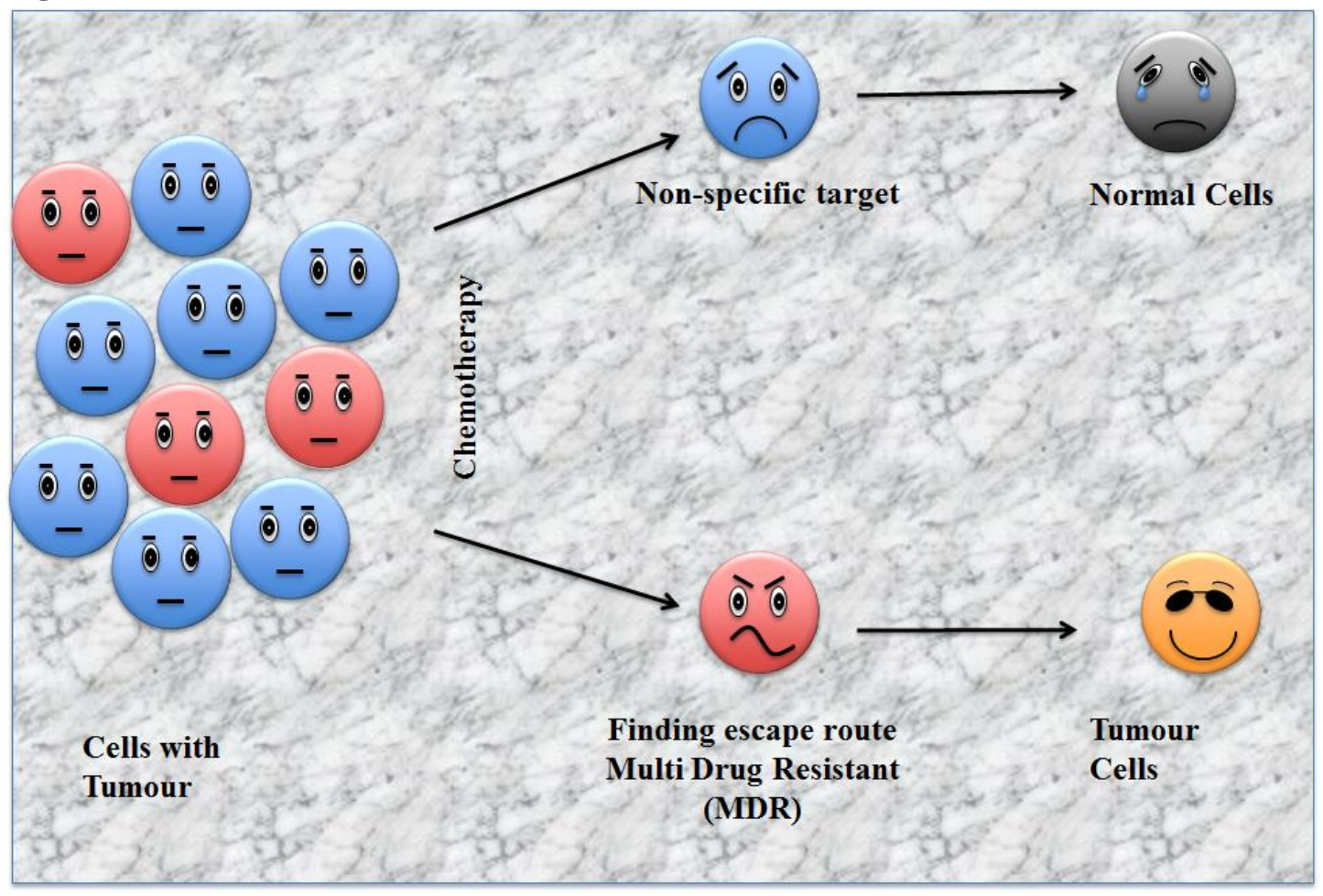

Figure 1: State-of-the-art conventional chemotherapy and its associated problems

One of the key problems associated with conventional chemotherapy is its unintentional toxicity for normal cells. Apart from the beneficial effects of killing cancer cells, anticancer drugs simultaneously destroy healthy tissue, resulting in systemic toxicity. The first course of chemotherapy may show highly beneficial effects. However a few cancer cells manage to find the escape route and often survive and proliferate against the drug. With the subsequent courses of highdose chemotherapy, the drug-defiant cells thrive, showing increasing resistance to the administered drug and finally displaying virtual invulnerability to the conventional chemotherapy. 


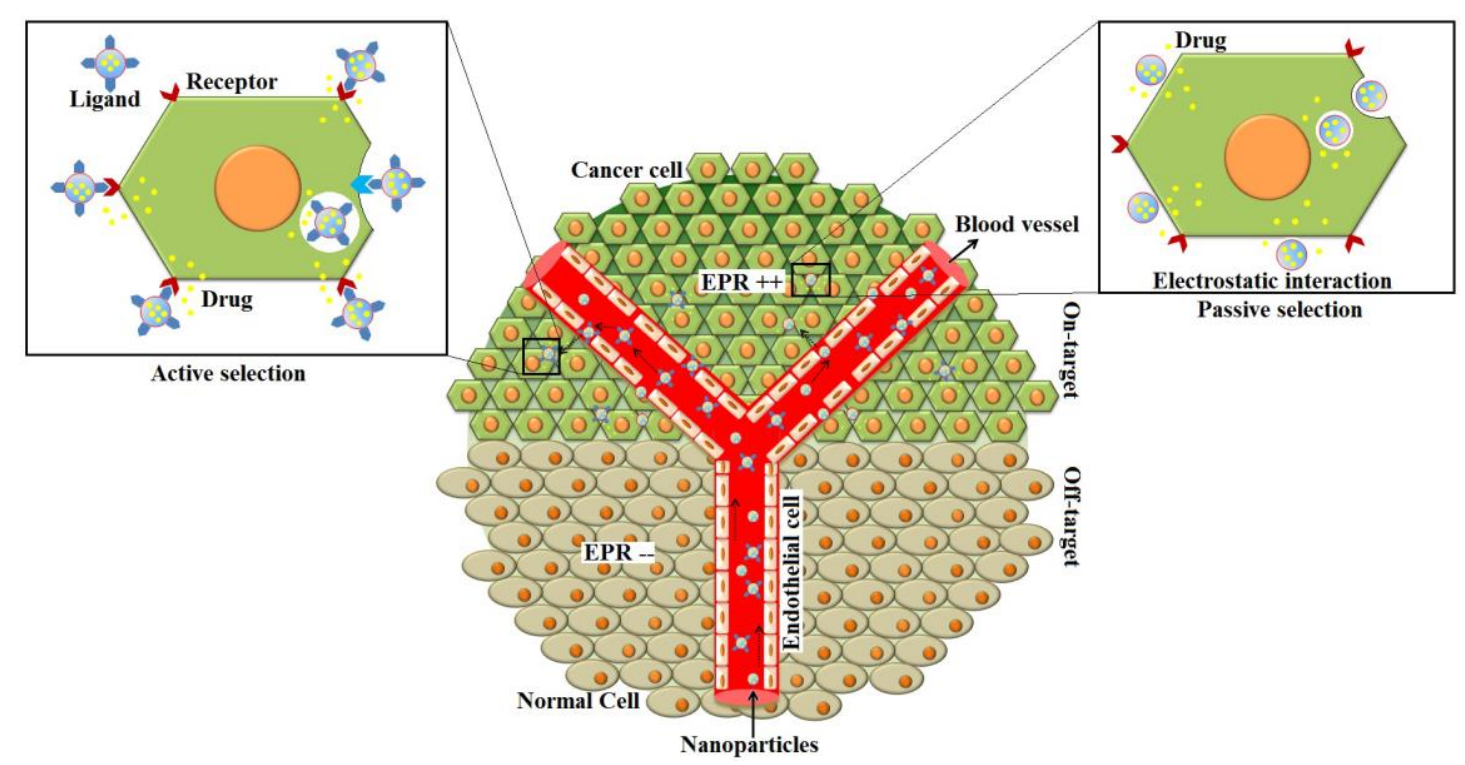

Figure 2: The mode of action for nanomaterials in cancer cell selection

Most of the conventional chemotherapeutic drugs have poor pharmacokinetic profiles and are unable to differentiate normal (Off-target) from the diseased cells (On-target), and are thus distributed non-specifically within the whole body, leading to systemic toxicity resulted with deleterious side effects. Due to the minute distinct characteristics of tumour microenvironment and tumour angiogenesis, it is possible to design nanotechnology-based drug delivery systems that can selectively target anticancer drugs to tumours. The mode of selection may be active (left half) or passive (right half). Nanomedicine can reach the tumour site passively through the leaky vasculature surrounding the tumours by the enhanced permeability and retention (EPR) effect (upper half). The newly developing endothelial cells with negative surface charge can be passively targeted due to electrostatic attraction to positively charged nanocarriers (upper-right). On the other hand active ligands grafted on the nano-surface allow active targeting by binding to the respective receptors present or overexpressed by cancer or angiogenic endothelial cells (upper left). As a result of the comparatively low EPR and lack of leaky vasculature, the healthy normal cells are unaffected by the nanotechnology-based approaches (lower half). 


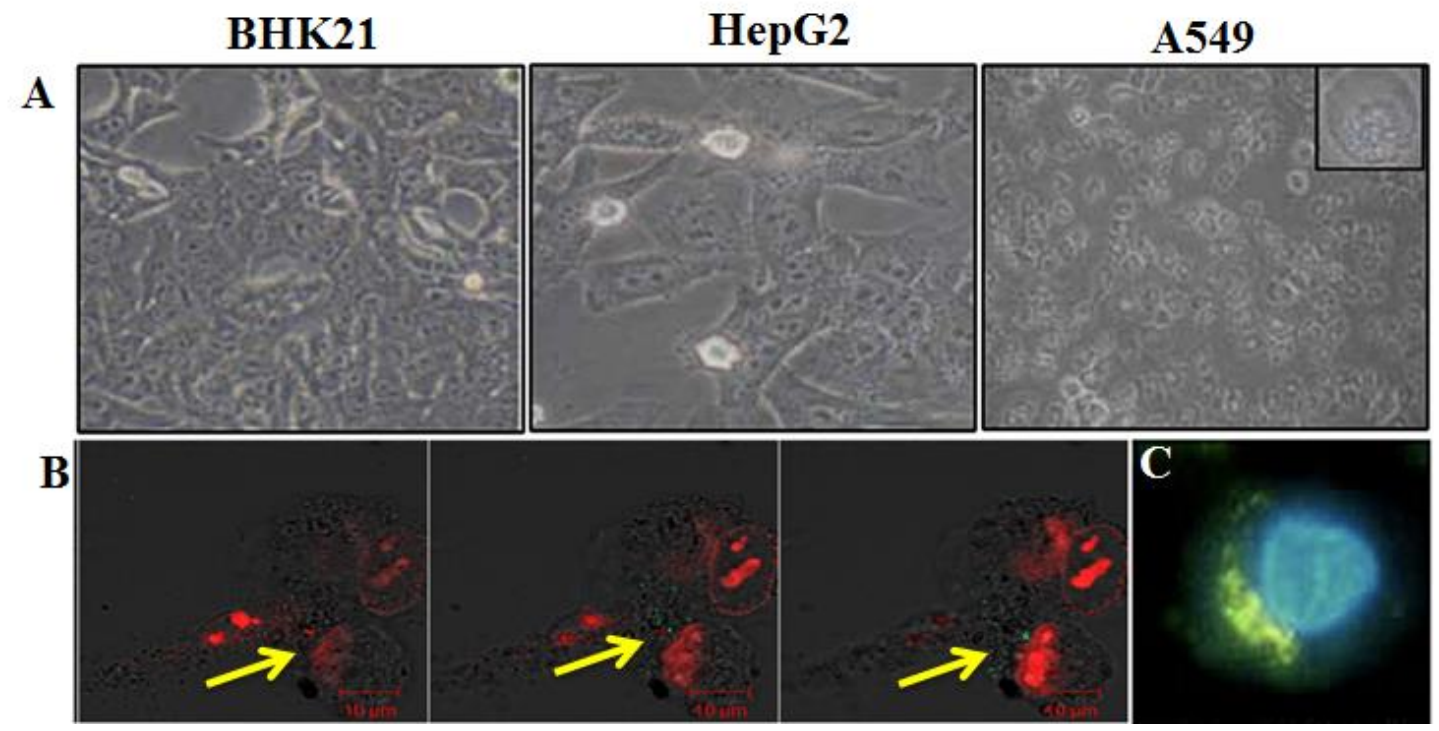

Figure 3: Cell selection by gold nanoparticles (GNPs):

(A) Phase contrast morphology of GNP-treated cancer cells. Only A549 cells are affected and change their morphology whereas another two cell lines (HepG2 and BHK21) are unaltered. Inset is the magnified view of the single A549 cell describing the round shaped morphology. (B) Confocal microscopic images of the selected A549 cells with Z-sectioning (left to right). (C) Asymmetric accumulation of GNP outside the nucleus (DAPI, 4',6-diamidino-2-phenylindole is a fluorescent stain that binds strongly to A-T rich regions in DNA, blue). Reprinted, with permission, from [35]. 


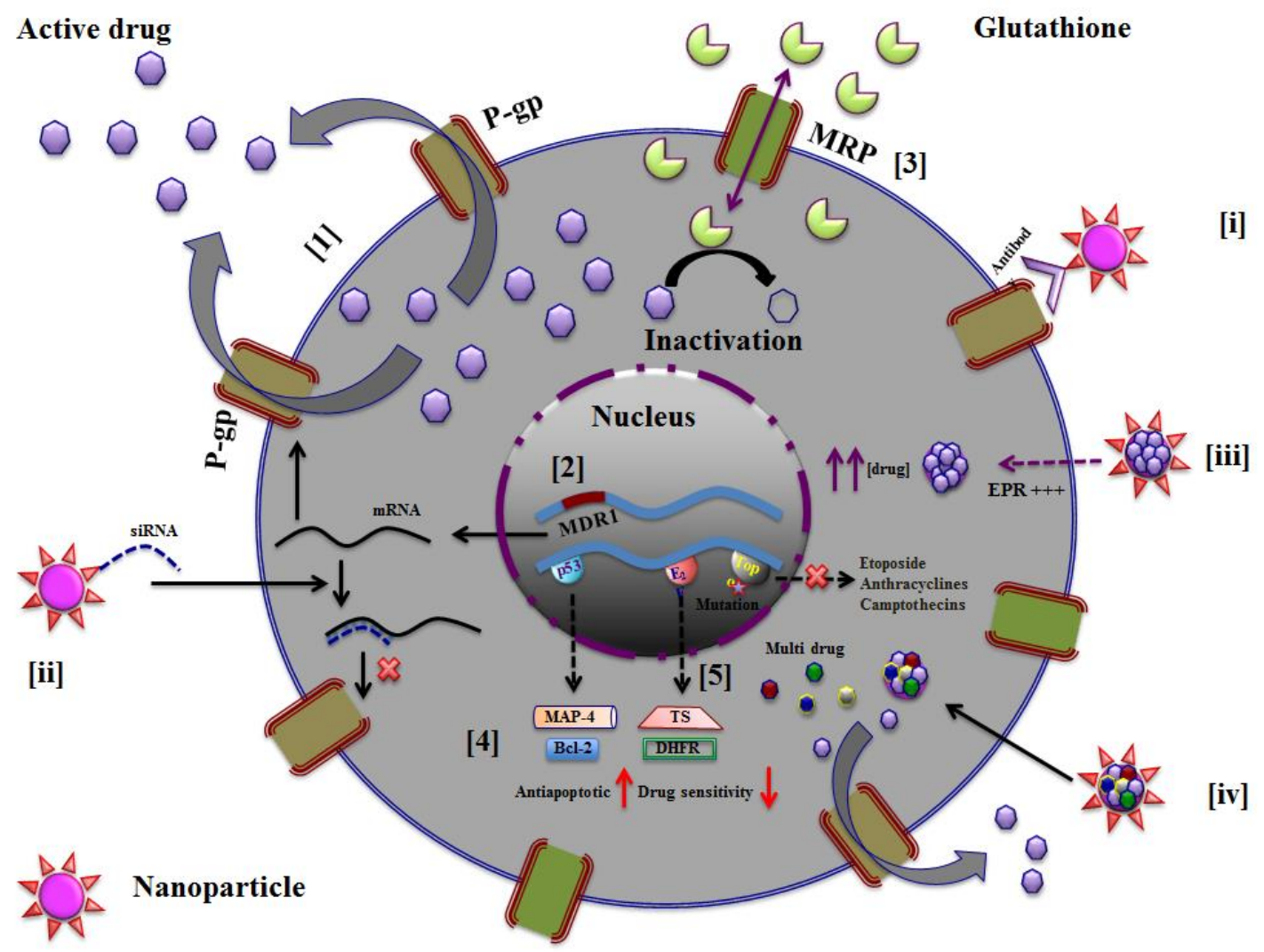

Figure 4: Multidrug resistance (MDR) mechanism and selection via nanotechnology:

Drug efflux by P-glycoprotein (P-gp) [1], an MDR1 gene product [2], or the MDR protein (MRP) can reduce the effective drug dose to sub-threshold levels. MRP cotransports glutathione, which can detoxify a variety of alkylating agents through neutralisation [3]. Nanotechnology offers several different approaches to overcome these challenges. The nanotechnology-based approach can selectively target P-gp to stop drug clearance [I and ii]; the local concentration of the drug can be increased due to the positive enhanced permeability and retention (EPR) effect and the amount of drug delivered by the nanocarrier [iii]; a combinatorial drug delivery system can be used for delivery of multiple drugs simultaneously to avoid clearance of all drug molecules [iv]. In MDR, p53 alters apoptotic signalling molecule Bcl-2 and cell cycle regulatory molecule microtubule-associated protein (MAP)4 [4]. The release of transcription factor E2F regulates drug sensitivity (e.g., methotrexate, and fluorouracil etc) by producing dihydrofolate reductase (DHFR) and thymidylate synthetase (TS). Mutations in topoisomerases (topo) generate resistance to anthracyclines and etoposide, which can be countered by combinatorial therapy with multiple drugs in a single nanoparticle system [iv]. 


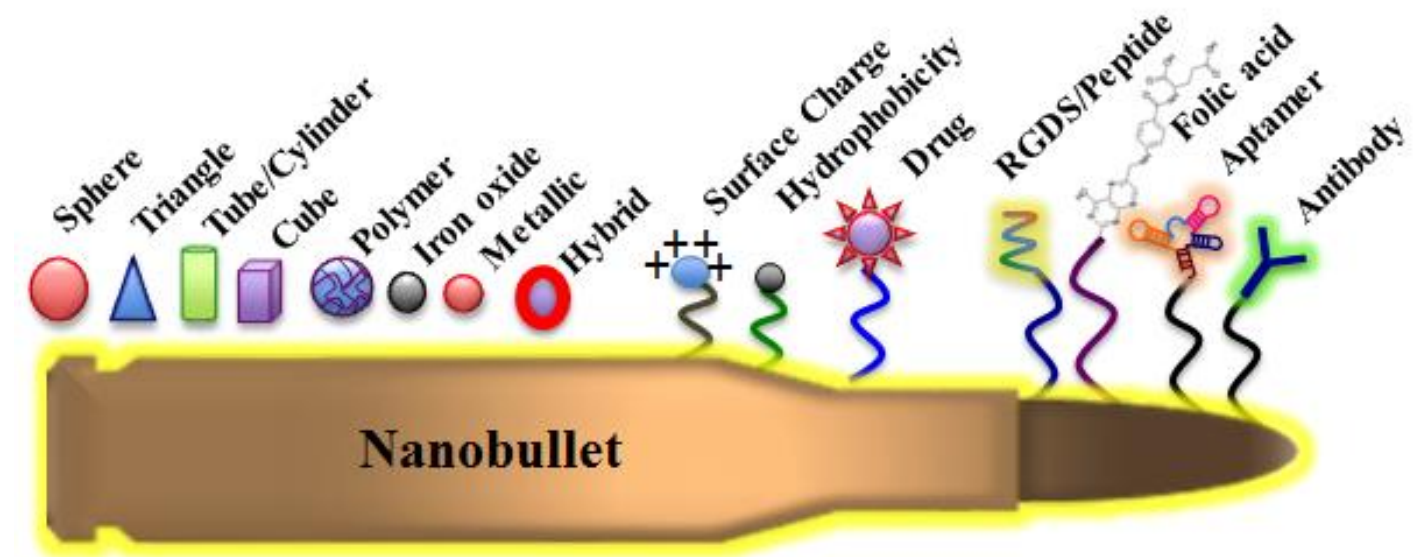

\section{Size-shape $>$ Composition $>$ Surface Functions $\gg$ Targeting}

Figure 5: Nano bullet

Multiplex nanoparticles with all the required functionalities for cancer management may be the way to realise the 'magic bullet' proposed 100 years ago by Paul Ehrlich to treat cancer [4].

\begin{tabular}{|c|c|c|c|c|c|}
\hline Cancer & Target & Probe & Methodology & Detection & Ref \\
\hline Prostate & PSA & $\begin{array}{l}\text { i) GNP } \\
\text { ii) Silicon } \\
\text { Nanowire } \\
\text { iii) Dip-Pen } \\
\text { Nanolithography }\end{array}$ & $\begin{array}{l}\text { Fluorescence } \\
\text { Label free } \\
\text { Resonance } \\
\text { Raman }\end{array}$ & $\begin{array}{l}0.032 \mathrm{pg} / \mathrm{mL} \\
5 \mathrm{fg} / \mathrm{mL} \\
25 \mathrm{pg} / \mathrm{mL}\end{array}$ & $\begin{array}{l}62 \\
63 \\
64\end{array}$ \\
\hline & PSMA & $\begin{array}{l}\text { GNR } \\
\text { PEDOT }\end{array}$ & $\begin{array}{l}\text { Optoacoustic } \\
\text { Electrochemical }\end{array}$ & $\begin{array}{l}\text { 3D cell model } \\
100 \mathrm{pM}\end{array}$ & $\begin{array}{l}65 \\
66\end{array}$ \\
\hline Breast & Her-2 & $\begin{array}{l}\text { magneto- } \\
\text { nanoclusters } \\
\text { Nano array }\end{array}$ & $\begin{array}{l}\text { Magnetic Imaging } \\
\text { Electrophoretic } \\
\text { particle } \\
\text { entrapment } \\
\text { system }\end{array}$ & $\begin{array}{l}10 \text { attomolar } \\
(\mathrm{aM})\end{array}$ & 67 \\
\hline Lung & CEA & Gold nanoshell & $\begin{array}{l}\text { Surface Enhanced } \\
\text { Raman Scattering }\end{array}$ & $\begin{array}{l}\mathrm{pg} / \mathrm{mL} \text { in } \\
\text { complex } \\
\text { mixture }\end{array}$ & 69 \\
\hline colon & KRAS & GNP & Colorometric & Naked eye & 70 \\
\hline
\end{tabular}

GNP, Gold nanoparticles; GNR, Gold nanorods; PEDOT, Poly(3,4-ethylenedioxythiophene) 
Table1: Molecular selection

\begin{tabular}{|c|c|c|c|}
\hline Cell & Probe & Detection & Ref \\
\hline \multirow[t]{6}{*}{ Breast } & GNP & SERS & 71 \\
\hline & Quantum dots & PL & 72 \\
\hline & Oval shaped GNP & Orthogonal & 73 \\
\hline & Quantum dots & Amplification & 74 \\
\hline & $\mathrm{CdS}$ & Two photon & 75 \\
\hline & SWCNT & $\begin{array}{l}\text { scattering } \\
\text { Electrochemical } \\
\text { Raman }\end{array}$ & 76 \\
\hline $\begin{array}{l}\text { Circulating } \\
\text { tumour cells }\end{array}$ & Nanobeads & $\begin{array}{l}\text { Lateral } \\
\text { Magnetophoresis }\end{array}$ & 77 \\
\hline $\begin{array}{l}\text { Human epithelial } \\
\text { cancer }\end{array}$ & $\mathrm{MnFe}_{2} \mathrm{O}_{4}$ magnetic nanocrystals & Fluorescence/ MRI & 78 \\
\hline $\begin{array}{l}\text { Human Lung } \\
\text { Cancer cells }\end{array}$ & $\begin{array}{l}\text { silica-coated superparamagnetic } \\
\text { nanoparticles }\end{array}$ & Fluorescence/ MRI & 79 \\
\hline $\begin{array}{l}\text { Ovarian cancer } \\
\text { cells }\end{array}$ & GNR & $\begin{array}{l}\text { Photoacoustic } \\
\text { Imaging }\end{array}$ & 80 \\
\hline
\end{tabular}

PL, Photoluminescence; SERS, Surface Enhanced Raman Scattering; SWCNT, Single wall carbon nanotubes

Table2: Cellular selection

\begin{tabular}{|c|c|c|c|}
\hline Name & Target & $\begin{array}{l}\text { Active } \\
\text { component }\end{array}$ & Nano System \\
\hline Myocet $^{\mathrm{TM}}$ & Breast Cancer & Doxorubicin & Liposomal \\
\hline Abraxane & $\begin{array}{l}\text { Metastatic Breast } \\
\text { Cancer }\end{array}$ & Paclitaxel & Albumin-bound \\
\hline Doxil & Ovarian Cancer & Doxorubicin & PEGylated liposomal \\
\hline Eligard & Prostate Cancer & Leuprolide acetate & $\begin{array}{l}\text { Biodegradable } \\
\text { polymer }\end{array}$ \\
\hline Caelyx & Kaposi's Sarcoma & Doxorubicin & PEGylated liposomal \\
\hline DaunoXome & Kaposi's Sarcoma & Daunorubicin & PEGylated liposomal \\
\hline $\begin{array}{l}\text { Genexol- } \\
\text { PM }\end{array}$ & Breast and Lung Cancer & Paclitaxel & Polymeric micelle \\
\hline Oncaspar & $\begin{array}{l}\text { Lymphoblastic } \\
\text { leukaemia }\end{array}$ & L-asparaginase & Polymeric micelle \\
\hline
\end{tabular}

Table3: Nanoscale delivery systems on the market

\begin{tabular}{|l|l|l|l|l|l|l|l|}
\hline \multicolumn{3}{|c|}{ Passive } & \multicolumn{3}{c|}{ Active } \\
\hline $\begin{array}{l}\text { Nanosys } \\
\text { tem }\end{array}$ & Drug & Cancer & $\begin{array}{l}\text { Clini } \\
\text { cal } \\
\text { trial }\end{array}$ & $\begin{array}{l}\text { Nanosys } \\
\text { tem }\end{array}$ & Cancer & $\begin{array}{l}\text { Targetin } \\
\text { g agent }\end{array}$ & $\begin{array}{l}\text { Clinica } \\
1 \text { trial }\end{array}$ \\
\hline SPI-77 & Cisplatin & $\begin{array}{l}\text { Epithelial } \\
\text { ovarian } \\
\text { cancer }\end{array}$ & $\begin{array}{l}\text { Phas } \\
\text { e II }\end{array}$ & $\begin{array}{l}\text { MCC- } \\
\text { DM1 }\end{array}$ & $\begin{array}{l}\text { Metast } \\
\text { atic } \\
\text { Breast }\end{array}$ & $\begin{array}{l}\text { Trastuzu } \\
\text { mab }\end{array}$ & $\begin{array}{l}\text { Appro } \\
\text { ved }\end{array}$ \\
\hline
\end{tabular}




\begin{tabular}{|c|c|c|c|c|c|c|c|}
\hline & & & & & Cancer & & \\
\hline $\begin{array}{l}\text { Marqibo } \\
\text { (®) }\end{array}$ & $\begin{array}{l}\text { Vincristi } \\
\text { ne } \\
\text { sulfate }\end{array}$ & $\begin{array}{l}\text { Non- } \\
\text { Hodgkin's } \\
\text { Lymphoma } \\
\text { and ALL }\end{array}$ & $\begin{array}{l}\text { Phas } \\
\text { e II }\end{array}$ & $\begin{array}{l}\text { BIND- } \\
014\end{array}$ & $\begin{array}{l}\text { Metast } \\
\text { atic } \\
\text { cancer }\end{array}$ & $\begin{array}{l}\text { Prostate- } \\
\text { specific } \\
\text { membran } \\
\text { e antigen } \\
\text { (PSMA) }\end{array}$ & Phase I \\
\hline $\begin{array}{l}\text { DepoCyt } \\
\text { (®) }\end{array}$ & $\begin{array}{l}\text { Cytarabi } \\
\text { ne }\end{array}$ & $\begin{array}{l}\text { Meningeal } \\
\text { Neoplasms }\end{array}$ & $\begin{array}{l}\text { Phas } \\
\text { e IV }\end{array}$ & $\begin{array}{l}\text { MBP- } \\
426\end{array}$ & $\begin{array}{l}\text { Metast } \\
\text { atic } \\
\text { solid } \\
\text { tumour }\end{array}$ & $\begin{array}{l}\text { Transferi } \\
\mathrm{n}\end{array}$ & Phase I \\
\hline $\begin{array}{l}\text { EndoTA } \\
\text { G® }\end{array}$ & $\begin{array}{l}\text { Paclitaxe } \\
1\end{array}$ & $\begin{array}{l}\text { Breast } \\
\text { cancer }\end{array}$ & $\begin{array}{l}\text { Phas } \\
\text { e II }\end{array}$ & $\begin{array}{l}\text { CALAA } \\
-01\end{array}$ & $\begin{array}{l}\text { Solid } \\
\text { Tumor } \\
\text { Cancer } \\
\mathrm{s} \\
\end{array}$ & $\begin{array}{l}\text { Human } \\
\text { transferri } \\
\text { n protein } \\
\text { (Tf) }\end{array}$ & Phase I \\
\hline $\begin{array}{l}\text { CRLX1 } \\
01\end{array}$ & $\begin{array}{l}\text { Cyclodex } \\
\text { trin }\end{array}$ & $\begin{array}{l}\text { Adenocarci } \\
\text { noma }\end{array}$ & $\begin{array}{l}\text { Phas } \\
\text { e II }\end{array}$ & $\begin{array}{l}\text { ALN- } \\
\text { VSP02 }\end{array}$ & $\begin{array}{l}\text { Advan } \\
\text { ced } \\
\text { Solid } \\
\text { Tumor } \\
\text { s and } \\
\text { Liver } \\
\text { cancer }\end{array}$ & VEGF & Phase I \\
\hline
\end{tabular}

VEGF, vascular endothelial growth factor

Table 4: Nanoparticle systems with active and passive selection undergoing

clinical trials (see: http://www.fda.gov/Drugs/default.htm and http://clinicaltrials.gov/ct2/home)

\begin{tabular}{|c|c|c|c|}
\hline $\begin{array}{l}\text { Nanoscale } \\
\text { formulation }\end{array}$ & Mode of actions & $\begin{array}{l}\text { Current } \\
\text { status }\end{array}$ & Ref \\
\hline Pluronic ${ }^{\circledR}$ & $\begin{array}{l}\text { Inhibition of transporters, } \\
\text { ATP depletion }\end{array}$ & $\begin{array}{l}\text { Clinical trial, } \\
\text { Phase-II }\end{array}$ & {$[81,82]$} \\
\hline Lipidic NP & $\begin{array}{l}\text { P-gp inhibition, endocytosis, } \\
\text { ATP depletion }\end{array}$ & $\begin{array}{l}\text { In vitro \& In } \\
\text { vivo }\end{array}$ & $\begin{array}{l}{[83-} \\
85]\end{array}$ \\
\hline $\begin{array}{l}\text { Hybrid NP (Polymer } \\
\text { and Lipid) }\end{array}$ & Phagocytosis & In vitro & {$[86,87]$} \\
\hline Liposome & Reverse MDR, bind to P-gp & In vitro & {$[88,89]$} \\
\hline
\end{tabular}

NP: Nanoparticles;

Table 5: Nanoparticle systems that target MDR 